\title{
Crisis management during anaesthesia: difficult intubation
}

\author{
A D Paix, J A Williamson, W B Runciman
}

Qual Saf Health Care 2005;14:e5 (http://www.qshc.com/cgi/content/full/14/3/e5). doi: 10.1136/qshc.2002.004135

See end of article for authors' affiliations .....................

Correspondence to: Professor W B Runciman, President, Australian Patient Safety Foundation, GPO Box 400, Adelaide, South Australia 5001 Australia; research@apsf. net.au

Accepted 11 January 2005
Background: Anaesthetists may experience difficulty with intubation unexpectedly which may be associated with difficulty in ventilating the patient. If not well managed, there may be serious consequences for the patient. A simple structured approach to this problem was developed to assist the anaesthetist in this difficult situation.

Objectives: To examine the role of a specific sub-algorithm for the management of difficult intubation. Methods: The potential performance of a structured approach developed by review of the literature and analysis of each of the relevant incidents among the first 4000 reported to the Australian Incident Monitoring Study (AIMS) was compared with the actual management as reported by the anaesthetists involved.

Results: There were 147 reports of difficult intubation capable of analysis among the first 4000 incidents reported to AIMS. The difficulty was unexpected in $52 \%$ of cases; major physiological changes occurred in $37 \%$ of these cases. Saturation fell below $90 \%$ in $22 \%$ of cases, oesophageal intubation was reported in $19 \%$, and an emergency transtracheal airway was required in $4 \%$ of cases. Obesity and limited neck mobility and mouth opening were the most common anatomical contributing factors.

Conclusion: The data confirm previously reported failures to predict difficult intubation with existing preoperative clinical tests and suggest an ongoing need to teach a pre-learned strategy to deal with difficult intubation and any associated problem with ventilation. An easy-to-follow structured approach to these problems is outlined. It is recommended that skilled assistance be obtained (preferably another anaesthetist) when difficulty is expected or the patient's cardiorespiratory reserve is low. Patients should be assessed postoperatively to exclude any sequelae and to inform them of the difficulties encountered. These should be clearly documented and appropriate steps taken to warn future anaesthetists.
D ifficult intubation occurs relatively commonly in association with general anaesthesia. Its true incidence is unknown but is estimated to be $1-3 \% .^{1}$ Approximately half of all cases are not predicted. ${ }^{1}$ A difficult intubation can be anticipated in a number of circumstances including a previous history of difficulty with intubation, syndromes known to be associated with difficulty to intubate, and some pathoanatomical states involving the head and neck region. Less reliable are anatomical hallmarks which may be sought at preoperative assessment including thyromental distance (see Appendix 1$)^{2}$ and the relative tongue/pharyngeal size (Mallampati test, see Appendix 2). ${ }^{3}$

If the anaesthetised patient cannot breathe spontaneously or the lungs cannot be otherwise ventilated by mask, then a series of manoeuvres must immediately be undertaken culminating, if necessary, in gaining direct transtracheal access to the airway. Such a structured approach is dealt with elsewhere in this set of articles. ${ }^{4}$

We concur with the recommendation of the American Society of Anesthesiologists' Task Force on the management of the difficult airway that all anesthesiologists should have a preformed strategy for intubation of the difficult airway. ${ }^{5}$

In 1993 a core crisis management algorithm, represented by the mnemonic COVER ABCD-A SWIFT CHECK, was proposed as the basis for a systematic approach to crisis management during anaesthesia (the $\mathrm{AB}$ precedes COVER for the non-intubated patient) where it is not immediately obvious what should be done or where actions taken have failed to remedy the situation. ${ }^{6}$ This was validated against the first 2000 incidents reported to the original Australian Incident Monitoring Study (AIMS). AIMS is an ongoing study which involves the voluntary anonymous reporting of any unintended incident which reduced or could have reduced the safety margin for a patient. ${ }^{7}$
It was concluded that, if this algorithm had been correctly applied, a functional diagnosis would have been reached within 40-60 seconds in 99\% of applicable incidents, and that the learned sequence of actions recommended by the COVER portion would have led to appropriate steps being taken to handle the $60 \%$ of problems relevant to this portion of the algorithm. ${ }^{6}$ However, this study also showed that the $40 \%$ of problems represented by the remainder of the algorithm, ABCD-A SWIFT CHECK, were not always promptly diagnosed or appropriately managed. ${ }^{6-8}$ It was decided that it would be useful, for these problems, to develop a set of specific sub-algorithms in an easy to use crisis management manual. ${ }^{9}$ This study reports on the place of the AB COVER CD-A SWIFT CHECK algorithm in the diagnosis and initial management of difficult intubation, provides an outline of a specific crisis management subalgorithm for this problem during anaesthesia, and provides an indication of the potential value of using this structured approach. It examines cases of difficult intubation from the first 4000 reports to AIMS and expands on the report that reviewed the data from the first 2000 reports. ${ }^{10}$

\section{METHODS}

Information of relevance to difficult endotracheal intubation was extacted from the first 4000 reports to AIMS. All incidents with the keywords "difficult intubation", "failed intubation", and "fibreoptic intubation" were analysed with respect to causes, management and outcome. The basis for the COVER-ABCD algorithm has been described in detail elsewhere. ${ }^{6}$ A specific sub-algorithm was developed (fig 1).

\section{RESULTS}

Of the first 4000 incidents reported to AIMS, 160 (4\%) dealt with problems with endotracheal intubation. There was one 


\section{DIFFICULT INTUBATION \\ REMEMBER, PATIENTS DO NOT DIE FROM FAILED INTUBATION - ONLY FAILED VENTILATION}

Always have skilled assistance, preferably another anaesthetist, when difficulty is expected or the patient's cardiorespiratory reserve is low.

\section{MANAGEMENT}

Call for skilled assistance

Call for the difficult intubation trolley

Maintain oxygenation at all times

Have someone feel the pulse and call out the $\mathrm{SpO}_{2}$.

If you cannot ventilate the lungs $\rightarrow$ page $14^{*}$

If you can ventilate by face mask, consider

waking up the patient $\mathrm{OR}$

maintaining anaesthesia and trying to intubate $(1)^{* *}$

Try basic manoeuvres first:

Optimise the head and neck position (2)

Try laryngeal manipulations such as "BURP" (3)

Try a well-lubricated gum elastic bougie or stylet (4)

Try different laryngoscope blades

If these fail:

Consider inserting an LMA (5)

Consider other techniques: Blind nasal

Retrograde

Lighted stylet

If an LMA is in place consider whether to proceed and whether steps

should be taken to secure endotracheal intubation (5)

Confirm correct placement of endotracheal tube.

\section{FURTHER CARE}

Review the situation

Exclude other complications (6)

There is a risk of awareness:

Go and see the patient in the ward

Explain again and reassure them (7)

Advise them to warn future anaesthesiologists (8).

The sub-algorithm forms a facing page of the

Crisis Management Manual28.

* Page references refer to the Crisis Management Manual ${ }^{28}$.

** Numbers in brackets refer to Notes in the right hand panel.

\section{NOTES:}

(1) Techniques will vary with the experience and familiarity with the techniques of the individual anaesthesiologist.

Avoid multiple attempts at laryngoscopy/intubation, as this may cause bleeding and laryngeal oedema, worsening the situation.

(2) This may require 2 assistants: one to apply pressure to the larynx and/or the back of the neck, the second to lift the head up.

(3) BURP refers to Backward Upward Rightward Pressure, as described by Knill (7). Knill, RL. Difficult laryngoscopy made easy with a "BURP", Can J Anaesth 1993; 40: 279-82.

(4) The most common aid to facilitate successful intubation in the AIMS series was the gum elastic bougie (46\%), followed by a stylet (23\%).

(5) The LMA is easy to insert and works well in about $95 \%$ of cases. It does not provide airway protection.

(6) Airway trauma

Pulmonary aspiration

Post-obstructive pulmonary oedema

Cardiovascular signs and symptoms.

(7) Provide written advice and document this in the medical record.

(8) Document the problem in the case notes and give the patient a letter to warn future anaesthetists. If a particular precipitating event was significant, or a particular action was useful in resolving the crisis, this should be clearly explained and documented. Consideration should also be given to a hazard alert device such as a Medic-alert ${ }^{\mathrm{T} M}$ bracelet.

These notes comprise a reverse side of a page of the Crisis Management Manual ${ }^{28}$.

Figure 1 Difficult intubation.

cardiac arrest which was successfully resuscitated. No deaths were reported. Sixty reports $(37 \%)$ involved emergency procedures and there were 43 "out of hours" incidents, mainly involving trainee anaesthetists. Further information is shown in table 1.

In 42 reports $(26 \%)$ there was an initial failure to intubate (table 1). This included 16 cases where a consultant had to be summoned from another location. In 14 of these 42 cases intubation was subsequently achieved, so endotracheal intubation was not achieved in 28 cases $(17 \%)$. There were 12 instances of an emergency airway procedure being performed. These included five tracheostomies (table 1) and successful placement of a laryngeal mask airway (LMA) in five patients who could not be ventilated.

There was difficulty with ventilation via a face mask in 23 reports (14\%), including eight of the 12 in which an emergency airway procedure was employed. In only two of these reports was difficulty with ventilation anticipated.
Thirteen reports contained insufficient information for further analysis, leaving 147 reports that were analysed with respect to cause, management and outcome. Difficulties in intubation were not predicted in 77 cases $(52 \%)$. It was judged that preoperative assessment of the airway was inadequate in 15 of these cases (table 2), and in one case fatigue was felt to be a significant co-factor. Omission of simple bedside tests such as checking for mouth opening and neck extension was commonly reported. There were 10 reports of errors of judgement despite appropriate preoperative assessment, nine of which involved trainees.

Drug errors were the primary cause of difficulty in 13 reports. This involved "failure" due to drug remaining in the line dead space (two reports) or decomposition following a prolonged period between preparation and usage (four reports), the wrong dose (four reports), and injection of the wrong drug (three reports). This information is summarised in table 2. 
Table 1 Difficult (including unsuccessful) endotracheal intubations from the first 4000 incidents reported to AIMS

\begin{tabular}{|c|c|c|c|c|}
\hline Planned surgery & $\begin{array}{l}\text { Difficult (failed) } \\
\text { intubation }\end{array}$ & $\begin{array}{l}\text { Difficult face mask } \\
\text { ventilation }\end{array}$ & Emergency airway & $\begin{array}{l}\text { Booked as } \\
\text { emergency cases }\end{array}$ \\
\hline General surgery & $50(17)$ & 12 & 2 (tracheostomy; LMA) & 26 \\
\hline Otorhinolaryngological & $25(5)$ & 5 & 2 (tracheostomy) & 2 \\
\hline Dental & 14 (1) & 1 & 1 (tracheostomy) & 1 \\
\hline Orthopaedic & $13(3)$ & 1 & - & 8 \\
\hline Obstetric & $10(3)$ & 1 & 2 (LMA) & 7 \\
\hline Urological & $9(3)$ & 1 & - & 4 \\
\hline Gynaecological & $8(3)$ & 1 & 1 (LMA) & 1 \\
\hline Plastic surgery & $8(2)$ & 1 & 1 (cricothyroid puncture) & 4 \\
\hline Neurosurgery & $8(2)$ & - & - & 3 \\
\hline Cardiothoracic & $7(0)$ & Not attempted & 1 (sternotomy for ruptured trachea) & 2 \\
\hline Vascular & $3(1)$ & - & 1 (LMA) & 1 \\
\hline Ophthalmological & $2(1)$ & - & - & - \\
\hline Others & $3(1)$ & - & 1 (semi-elective tracheostomy) & 1 \\
\hline Total & $160(42)$ & 23 & 12 & 60 \\
\hline
\end{tabular}

Table 3 summarises the reported intubation aids in the 132 reports where endotracheal intubation was achieved. In addition, simple manoeuvres alone such as repositioning the patient, correctly applied cricoid pressure, and the use of "BURP" (backward, upward, right ("ward") pressure on the larynx) enabled intubation in 16 cases $(11 \%) .{ }^{11}$

Table 4 shows the perceived contributing factors among the difficult intubations reported to AIMS. The three most common factors were obesity (24 cases), limited neck mobility, and limited mouth opening. These were also the most commonly reported factors in the analysis of the first 2000 reports to AIMS. ${ }^{10}$

The reported complications are shown in table 5. The two most commonly reported complications were desaturation $<90 \%(22 \%)$ and oesophageal intubation (19\%). Three unrecognised oesophageal intubations were reported, all in association with failure to confirm endotracheal tube placement by capnography in the presence of "normal" breath sounds upon auscultation. There were nine reports of gastrooesophageal reflux with aspiration, two of which were in association with a failure to intubate. There were two reports of awareness in the series, although the true incidence may be considerably higher. Epistaxis during attempts at blind nasal intubation occurred in two reports, making intubation even more difficult. Minor physiological changes, such as coughing and bucking, or desaturation not less than $90 \%$ were reported in 65 cases $(44 \%)$. In 18 cases $(12 \%)$ there were no significant changes in physiology. Sequelae were not recorded in 10 of the 147 cases $(7 \%)$.

\section{DISCUSSION}

Airway management and endotracheal intubation are fundamental skills for the safe conduct of anaesthesia. The true incidence of difficult intubation in anaesthetic practice is unknown, but is typically estimated at being between $1 \%$ and $3 \% .{ }^{1}$ Difficult intubation often arises unexpectedly, as was the case in $52 \%$ of incidents in this series. As even the most thorough preoperative assessment of the airway will fail to detect some difficult intubations, every anaesthetist should have a predetermined strategy for dealing with this situation.

Protocols for the management of difficult intubations previously published by AIMS ${ }^{10}$ and by the American Society for Anesthesiologists' Task Force on the Management of the Difficult Airway ${ }^{5}$ recommend a pre-learned strategy and emphasise the importance of maintaining ventilation; patients do not die from a failure to intubate but from a failure to ventilate.

In this series the most common remediable cause of unpredicted difficulty with intubation occurred in the setting of inadequate preoperative assessment. The existing bedside tests that look for anatomical indicators of difficulty-such as the Patil measurement of thyromental distance, ${ }^{2}$ the Mallampati test, ${ }^{3}$ and the Wilson scoring system ${ }^{12}$ (see Appendices 1 and 2)-appear, from our data, to lack sensitivity and specificity, making their usefulness limited. However, performing such tests would have detected the 32 cases with limited mouth opening and/or neck extension and might have prevented unexpected difficulties in these cases. It has been suggested that combining these tests improves the predictive power, with one group of investigators claiming $100 \%$ accuracy in their series..$^{13}$ More recently, Naguib and colleagues identified four clinical risk factors that correlate with difficult laryngoscopy and intubation (positive predictive value (PPV) 87.5\%): thyromental distance, thyrosternal distance, neck circumference, and Mallampati class. ${ }^{14}$ Combining these with a series of radiological measurements increased the PPV to $95.8 \%$.

Simultaneous difficulty with ventilation via a face mask occurred in $14 \%$ of reports. Emergency airways were required in nearly half of these (43\%). Five emergency tracheotomies were performed, two involving patients with supraglottic tumours. Another patient required a cricothyroid puncture. Reports of the use of laryngeal masks in this setting occurred in five cases. The previous analysis of 2000 incidents in 1993

Table 2 Unpredicted difficult intubation

\begin{tabular}{|c|c|c|c|}
\hline \multirow[b]{2}{*}{ Primary cause } & \multirow[b]{2}{*}{ No } & \multicolumn{2}{|c|}{ Grade of anaesthetist } \\
\hline & & Consultant & Trainee \\
\hline No obvious cause & 38 & 25 & 13 \\
\hline Inadequate preoperative assessment & 15 & 9 & 6 \\
\hline Drug errors & 13 & 6 & 7 \\
\hline Errors of judgement/experience & 10 & 1 & 9 \\
\hline Fatigue & 1 & 0 & 1 \\
\hline Total & 77 & 41 & 36 \\
\hline
\end{tabular}


Table 3 Reported usage of commonly used aids to difficult endotracheal intubation in the first 4000 incidents reported to AIMS

\begin{tabular}{lllllll}
\hline Type of surgery & $\begin{array}{l}\text { Gum elastic } \\
\text { bougie }\end{array}$ & Introducer & $\begin{array}{l}\text { Fibreoptic } \\
\text { endoscope }\end{array}$ & $\begin{array}{l}\text { Change of } \\
\text { laryngoscope* }\end{array}$ & Magill forceps & Rigid bronchoscope \\
\hline General surgical & 13 & 8 & 3 & 3 & 1 & 1 \\
Otorhinolaryngological & 3 & 2 & 2 & 2 & - & - \\
Dental & 3 & 1 & 3 & 1 & - & - \\
Orthopaedic & 7 & 1 & 1 & 1 & - & - \\
Obstetric & 1 & 1 & - & - & - & - \\
Urological & 1 & 2 & - & - & - & - \\
Gynaecological & 3 & 1 & 2 & - & 3 & 1 \\
$\begin{array}{l}\text { Plastic and reconstructive } \\
\text { Others }\end{array}$ & 3 & 2 & 13 & 8 & & \\
Total (n=80) & 37 & 18 & & & & \\
\hline
\end{tabular}

had no reports of the use of this device. ${ }^{10}$ Its appearance now probably reflects greater application of-and familiarity with-the laryngeal mask airway and its potentially life saving role in this situation. There were only two reports in this series where difficulties in intubation and mask ventilation were predicted. Both were managed with an awake fibreoptic intubation technique.

Time honoured methods of managing the difficult intubation are being supplanted by the use of fibreoptic intubating techniques where difficulty is predicted, and the laryngeal mask airway where it is not. Mention of the use of blind nasal intubation (six reports), Magill's forceps (three reports), and of the rigid bronchoscope (one report) was infrequent. More recently, several laryngoscope blades for difficult intubation such as the Bellhouse ${ }^{15}$ and McCoy ${ }^{16}$ blades and the Bullard laryngoscope have been described. They give the anaesthetist more choice in managing these problems. However, trainee anaesthetists may lack appreciation of simple and effective techniques, as there were a number of instances where consultants rapidly dealt with problems by repositioning the patient ("sniffing the morning air"), using laryngeal manipulations such as "BURP", " or by the use of stylets or blind nasal intubation as well as other laryngoscope blades.

The use of the gum elastic bougie was widespread in this series and successfully aided intubation in $46 \%$ of cases. A stylet was successful in a further $23 \%$. These two simple aids allowed most problems to be solved and so should be considered early, as soon as difficulties arise. In an editorial in 1993 on the gum elastic bougie, Wilson ${ }^{17}$ wrote: "... the

Table 4 Factors identified by reporters as contributing to intubation difficulty from the first 4000 incidents reported to AIMS

\begin{tabular}{ll}
\hline Contributing factor & No of reports \\
\hline Obesity & 24 \\
Limited neck mobility & 17 \\
Limited mouth opening & 15 \\
Inexperience of laryngoscopist & 14 \\
Inadequate assistance & 13 \\
Drug errors & 13 \\
Poor/prominent dentition & 11 \\
Equipment deficiencies & 8 \\
Laryngeal tumour & 8 \\
Recent traumatic intubation & 8 \\
Neck mass & 3 \\
Beard & 2 \\
Masseter spasm & 2 \\
Others* & 5 \\
\hline
\end{tabular}

*Cervical spine instability, facial carcinoma, congenital microsomia, ruptured trachea, and hair in a "bun" were each reported on one occasion. success of this simple tool has quietly but radically altered anaesthetic practice, as all that is now required is a view of the epiglottis...". ${ }^{17}$

Weiss ${ }^{18}$ has described an endoscopic system which allows visualisation by substitution of the gum elastic bougie with a flexible endoscope. It provides assistance where direct laryngoscopic view of the vocal cords is impaired. Further experience is necessary in adults as it dealt only with simulated difficult paediatric airways. It has the potential advantage of converting a blind technique (bougie assisted intubation) into a visualised one.

Several devices are available which were not mentioned in any of the incident reports in our series. All may have a role to play, but experience in their use and an understanding of their suitability for different airway problems is essential before considering their use in what can be a stressful situation.

The cuffed oropharyngeal airway (COPA) may be of assistance where problems with ventilation occur. A French group $^{19}$ have reported its use in conjunction with both the gum elastic bougie and the fibreoptic laryngoscope to aid intubation.

The intubating laryngeal mask airway (ILMA) is a device designed specifically to aid in blind intubation. Clinical trials confirm its ease of rapid insertion and reliable ventilation in almost all patients..$^{20}$ Furthermore, (blind) intubation rates of 93-99\% are reported. ${ }^{20}$ A Canadian group ${ }^{20}{ }^{21}$ has reported multiple attempts at intubation being necessary in some patients, and concluded that experience in the technique would improve the success rate. We advise caution in viewing

Table 5 Complications reported in association with difficult intubation from the first 4000 incidents reported to AIMS

\begin{tabular}{lc}
\hline Complication & No of reports \\
\hline Arterial desaturation $<90 \%$ & 33 \\
Oesophageal intubation & 28 \\
Central cyanosis & 10 \\
Regurgitation & 9 \\
Bronchospasm & 9 \\
Laryngospasm & 7 \\
Dental damage & 4 \\
Cardiac arrhythmias* & 3 \\
Endobronchial intubation & 3 \\
Epistaxis & 2 \\
Pharyngeal trauma & 2 \\
Awareness & 2 \\
Masseter spasm & 2 \\
Others $\dagger$ & 4 \\
Total & 118 \\
\hline *There were two reports of bigeminy and one of \\
supraventricular tachycardia. \\
$\dagger$ Electrocardiographic signs of ischaemia, cardiac arrest, a \\
lacerated tongue, and an oesophageal tear were each \\
recorded on one occasion.
\end{tabular}


this device as a universal panacea to the problem of difficult intubation. Our series confirms that problems arise from repeated attempts at intubation. A blind technique cannot be recommended where there is abnormal upper airway anatomy such as tumours, abscesses, or previous deforming surgery or trauma.

The Combitube is another airway management device, well established in the emergency medicine setting, that anaesthetists may use. ${ }^{22}{ }^{23}$ It can be sited without the need for direct laryngoscopy. Its use is associated with a higher incidence of complications than the laryngeal mask airway but it can prevent gastric aspiration. Pharyngeal trauma is common, ${ }^{22}{ }^{23}$ probably due to the $85 \mathrm{ml}$ pharyngeal cuff. Valve-like upper airway obstruction by the aryepiglottic folds has been described. ${ }^{23}$ The use of this device should perhaps be restricted to emergency situations but, again, familiarity is essential.

The previous series, which looked at difficult intubation in $1993,{ }^{10}$ highlighted the problem of the inexperienced and/or lone anaesthetist having to cope with a difficult intubation. In nearly one third of cases $(n=50)$ the anaesthetist was a trainee with $60 \%$ of these incidents occurring out of hours. In $25 \%$ of cases serious difficulty occurred despite the preoperative prediction of a difficult airway. It would appear that a pre-considered approach to difficult intubation continues to be lacking. A plan of management is shown in fig 1 ; it discourages prolonged or traumatic attempts at intubation which may create additional problems. Always have skilled assistance, preferably another anaesthetist, when difficulty is expected or the patient's cardiorespiratory reserve is low. ${ }^{24}$

\section{Key messages}

- All anaesthetists should have a pre-formed strategy for intubation of the difficult airway.

- $160(4 \%)$ of the first 4000 AIMS reports dealt with endotracheal intubation problems. There were no deaths.

- In 28 reports (17\%) endotracheal intubation was not achieved despite more than one attempt.

- An emergency airway procedure was performed in 12 instances (five tracheostomy, five laryngeal mask airway).

- Difficult face mask ventilation occurred in 23 reports (14\%), eight requiring an emergency airway procedure; in 21 of these 23 reports ventilation difficulty was not anticipated.

- Intubation difficulties were not predicted in $52 \%$ of the 147 reports capable of full analysis. Omission of simple bedside tests beforehand was commonly reported.

- Drug errors were the primary cause in 13 cases.

- Simple manoeuvres alone (positioning, correct cricoid pressure, "BURP") enabled intubation in 16 cases (11\%).

- The most useful aids were a gum elastic bougie and an introducer.

- The three most common contributing factors were obesity, limited neck mobility, and limited mouth opening.

- Desaturation and oesophageal intubation were the most common complications.

- Inadequate preoperative assessment was the most common remediable cause.
A number of avoidable factors other than inadequate preoperative assessment resulted in difficulties. Drug errors occurred in 13 cases and, in all of them, correction of the error allowed intubation to be achieved. Equipment deficiencies-largely due to "failure to check" such as no introducer in the theatre and failure of the laryngoscope light-occurred in six cases. Inadequate or poorly trained assistants were judged to be a contributing factor in 10 cases. The responsibility in all of these instances clearly rests with the anaesthetist.

The sequelae of difficult/failed intubation range from the trivial to loss of life. In this series no deaths occurred, but major physiological sequelae occurred in 54 reports (37\%). Arterial desaturation less than $90 \%$ as measured by pulse oximetry occurred in $22 \%$ of reports, and in a further 10 cases central cyanosis without specific oximetry measurement was reported. The incidence of oesophageal intubation in this series was 19\% (28 reports). Of more concern was the failure to detect oesophageal intubation in three cases where a capnograph was not used. All these patients had apparently normal breath sounds on chest auscultation. Detection in these cases was from persistent severe desaturation. The capnograph is the only monitor that will reliably detect oesophageal intubation within a few breaths. The Australian and New Zealand College of Anaesthetists has recommended that a "carbon dioxide monitor should be exclusively available for every intubated and/or ventilated patient". ${ }^{25}$

Difficulty with intubation is a relatively common occurrence with general anaesthesia and is often unpredicted, so every anaesthetist should have a pre-learned strategy for dealing with this problem. ${ }^{26}{ }^{27}$ The data collected in this series confirm that early assistance and use of simple measures such as repositioning the head, trying laryngeal pressure, and the use of simple aids such as a well lubricated bougie or stylet will enable resolution of the problem in most cases. The structured approach presented in fig 1 reflects this, emphasising simple methods and avoidance of repeated attempts at intubation that may create additional problems. ${ }^{26}$ These patients should be assessed postoperatively to exclude any sequelae and to inform them of the difficulties encountered. The problem should be documented clearly in the case notes and the patient given a letter to warn future anaesthetists. If a particular precipitating event was significant, or a particular action was useful in resolving the crisis, this should also be clearly explained and documented. ${ }^{24}$ Finally, a hazard alert device such as a Medic-alert ${ }^{\mathrm{TM}}$ bracelet should also be considered.

\section{ACKNOWLEDGEMENTS}

The authors would like to thank all the anaesthetists in Australia and New Zealand who contributed to the 4000 incident reports upon which this and the other 24 papers in the Crisis Management Series are based. The coordinators of the project also thank Liz Brown for preparing the draft of the original Crisis Management Manual; Loretta Smyth for typing; Monica Bullock RN for earlier coding and classifying of data; Dr Charles Bradfield for the electronic version of the algorithms; Dr Klee Benveniste for literature research; and Drs Klee Benveniste, Michal Kluger, John Williamson and Andrew Paix for editing and checking manuscripts.

\section{Authors' affiliations}

A D Paix, Consultant Anaesthetist, Princess Royal University Hospital, Orpington, Kent, UK

J A Williamson, Consultant Specialist, Australian Patient Safety Foundation; Visiting Research Fellow, University of Adelaide and Royal Adelaide Hospital, Adelaide, South Australia, Australia

W B Runciman, Professor and Head, Department of Anaesthesia and Intensive Care, University of Adelaide and Royal Adelaide Hospital, Adelaide, South Australia, Australia 
This study was coordinated by the Australian Patient Safety Foundation, GPO Box 400, Adelaide, South Australia 5001, Australia.

\section{APPENDIX 1 THYROMENTAL DISTANCE AND WILSON SCORING SYSTEM}

\section{Thyromental distance}

The thyromental distance is the inframental distance anterior to the larynx which determines how easily the laryngeal and pharyngeal axes will fall into line with atlanto-occipital extension. A distance of $<6 \mathrm{~cm}$ (approximately three finger breadths) suggests laryngoscopy may be difficult.

\section{Wilson scoring system}

Wilson and colleagues ${ }^{12}$ found five useful risk factors, measured at three levels of severity, that could be used to predict difficulty with intubation. Depending on the threshold chosen, a high percentage of truly difficult intubations can be detected, however this is at a cost of increasing the false positive rate.

The risk factors identified were as follows:

- weight;

- head and neck movement;

- jaw movement (mandibular protrusion, inter-incisor gap);

- prominent maxillary teeth ("buck teeth");

- receding mandible.

\section{APPENDIX 2 MALLAMPATI TEST}

Mallampati and colleagues ${ }^{3}$ described clinical signs to predict difficult intubation in 1983:

- The patient sits upright, head in the neutral position.

- The mouth is opened as widely as possible and the tongue is maximally protruded, without phonating.

- The observer sits opposite at eye level and inspects the pharyngeal structures.

The airway is classified according to the structures seen. Mallampati et al described three grades, but the commonly used assessment consists of four grades as modified by Samsoon and Young. ${ }^{27}$ The four grades are as follows:

(I) soft palate, fauces, uvula, pillars;

(II) soft palate, fauces, uvula;

(III) soft palate, base of uvula;

(IV) soft palate not visible at all.

It should be noted that a class I view nearly always predicts easy intubation and a class IV view a difficult intubation. Intermediate classes (II and III) are associated with a wide range of degrees of difficulty with intubation.

\section{REFERENCES}

1 Otto CW. Tracheal intubation. In: Nunn JF, Utting JE, Brown BR, eds. General anaesthesia, 5th ed. London: Butterworths, 1989:533-4.
2 Patil VU, Stehling LC, Zauder HL. Fiberoptic endoscopy in anesthesia. Chicago: Year Book Medical Publishers, 1983.

3 Mallampati SR, Gatt SP, Gugino LD, et al. A clinical sign to predict difficult tracheal intubation: a prospective study. Can Anaesth Soc J 1985;32:429-34

4 Visvanathan T, Kluger MT, Webb RK, et al. Crisis management during anaesthesia: obstruction of the natural airway. Qual Saf Health Care 2005; 14:e2.

5 American Society of Anesthesiologists Task Force on Management of the Difficult Airway. Practice guidelines for management of the difficult airway. Anesthesiology 1993;78:597-602.

6 Runciman WB, Webb RK, Klepper ID, et al. Crisis management: validation of an algorithm by analysis of 2000 incident reports. Anaesth Intensive Care 1993;21:579-92

7 Webb RK, Currie M, Morgan CA, et al. The Australian Incident Monitoring Study: an analysis of 2000 incident reports. Anaesth Intensive Care 1993;21:520-8.

8 Webb RK, van der Walt JH, Runciman WB, et al. Which monitor? An analysis of 2000 incident reports. Anaesth Intensive Care 1993;21:529-42.

9 Runciman WB, Kluger MT, Morris RW, et al. Crisis management during anaesthesia: the development of an anaesthetic crisis management manual. Qual Saf Health Care 2005; 14:e1.

10 Williamson JA, Webb RK, Szekely SM, et al. Difficult intubation: an analysis of 2000 incident reports. Anaesth Intensive Care 1993;21:602-7.

11 Knill RL. Difficult laryngoscopy made easy with a "BURP". Can J Anaesth 1993;40:279-82.

12 Wilson ME, Spiegelhalter D, Robertson JA, et al. Predicting difficult intubation. Br J Anaesth 1988:61:211-6.

13 Bellhouse CP, Doré C. Criteria for estimating likelihood of difficulty of endotracheal intubation with the Macintosh laryngoscope. Anaesth Intensive Care 1988; 16:329-37.

14 Naguib M, Malabarey T, AlSatli RA, et al. Predictive models for difficult laryngoscopy and intubation. A clinical, radiologic and three-dimensional computer imaging study. Can J Anaesth 1999;46:748-59.

15 Bellhouse CP. An angulated laryngoscope for routine and difficult tracheal intubation. Anesthesiology 1988;69:126-9.

16 McCoy EP, Mirakhur RK. The levering laryngoscope. Anaesthesia 1993;48:516-9.

17 Wilson ME. Predicting difficult intubation. Br J Anaesth 1993;71:333-4.

18 Weiss M. Hartmann K, Fischer J, et al. Video-intuboscopic assistance is a useful aid to tracheal intubation in paediatric patients. Can $J$ Anaesth 2001;48:691-6.

19 Boisson-Bertrand D. Role of the cuffed oropharyngeal airway in difficult intubations (in French). Rev Med Suisse Romande 1999;1 19:919-20.

20 Caponas G. Intubating laryngeal mask airway. Anaesth Intensive Care 2002;30:551-69.

21 Van Vlymen JM, Coloma M, Tongier WK, et al. Use of the intubating laryngeal mask airway. Are muscle relaxants necessary? Anaesthesiology 2000;93:340-5.

22 Oczenski W, Krenn H, Dahaba AA, et al. Complications following the use of the Combitube, tracheal tube and laryngeal mask airway. Anaesthesia 1999:54:1161-5.

23 Jaehnichen G, Golecki N, Lipp MD. A case report of difficult ventilation with the Combitube: valve-like upper airway obstruction confirmed by fibreoptic visualisation. Resuscitation 2000:44:71-4.

24 Mellado PF, Thunedborg LP, Swiatek F, et al. Anaesthesiological airway management in Denmark: assessment, equipment and documentation. Acta Anaesthesiol Scand 2004;48:350-4.

25 Australian and New Zealand College of Anaesthetists. Policy Statement 18: Recommendations on monitoring during anaesthesia. Melbourne: ANZCA, 2000. Also available at http://www.anzca.edu.au/publications/profdocs/ profstandards/ps18_2000.htm (accessed 20 December 2004).

26 Heidegger T, Gerig HJ, Keller C. Comparison of algorithms for management of the difficult airway (in German). Anaesthesist 2003;52:381-92.

27 Samsoon GL, Young JR. Difficult tracheal intubation: a retrospective study. Anaesthesia 1987; 42:487-90.

28 Australian Patient Safety Foundation. Crisis Management Manual: COVER $A B C D$ A SWIFT CHECK. Adelaide: Australian Patient Safety Foundation, 1996, 74 pp. Available at http://www.apsf.net.au/anaesthesia.htm (accessed 6 September 2004). 